\title{
DOENÇA OU FEITIÇO? UM RELATO SOBRE 0 FENÔMENO DO "MAL-ESTAR" E A EXPERIÊNCIA MIGRATÓRIA NA METRÓPOLE PAULISTANA
}

\author{
ANA ELISA DE FIGUEIREDO BERSANI
}

\begin{abstract}
RESUMO
Este ensaio parte do relato etnográfico para desenvolver a reflexão acerca da experiência de imigrantes negros, de origem haitiana, em São Paulo, problematizando dinâmicas sociais que envolvem a gestão da saúde, da doença e do sofrimento em um contexto marcado por constantes transformações e intensos fluxos globais de pessoas e conhecimentos. 0 exame desse complexo emaranhado de conexões é 0 objeto de pesquisa da antropóloga que realiza trabalho de campo desde 2016 junto à diáspora haitiana e às organizações que integram a Rede de Cuidados aos Imigrantes e Refugiados na metrópole paulistana. Nesse trabalho, aspectos do universo mágico-religioso são tomados enquanto imprescindíveis à compreensão dos processos vividos em solo brasileiro.
\end{abstract}

\section{PALAVRAS-CHAVE \\ Migração. Sofrimento. Doença. Feitiço.
ILLNESS OR SORCERY? NOTES ON THE "MALAISE" PHENOMENON AND THE MIGRATORY EXPERIENCE IN THE CITY OF SÃO PAULO

\begin{abstract}
In this ethnographic essay I aim to develop a reflection about the experience of black immigrants from Haiti living in São Paulo, Brazil. It seeks to problematize the social dynamics involving health, illness and suffering management in a context marked by constant transformations and intense flows of people and knowledge. The examination of this complex tangle of connections is explored through research conducted since 2016 with the Haitian diaspora and the Network for the Immigrant and Refugee Care in São Paulo. In this work, aspects of the magical-religious universe are taken as essential to the understanding of the lived processes and the diasporic experience.
\end{abstract}

\section{KEYWORDS}

Migration. Suffering. Disease. Witchcraft.

\section{MALADIE OU SORT? LE PHÉNOMÈNE DE «MALAISE» ET L'EXPÉRIENCE MIGRATOIRE DANS LA VILLE MÉTROPOLITAINE DE SÃO PAULO}

\section{RÉSUMÉ}

Cet essai part du rapport ethnographique pour développer la réflexion sur l'expérience des immigrés noirs, d'origine haïtienne, à São Paulo, problématisant les dynamiques sociales impliquant la gestion de la santé, de la maladie et de la souffrance dans un contexte marqué par des transformations constantes et des flux intenses de personnes et connaissances. L'examen de cet enchevêtrement complexe de relations fait l'objet de recherches de l'anthropologue qui mène depuis 2016 des travaux sur le terrain avec la diaspora haïtienne et les organisations qui composent le réseau de soin et attention aux immigrants et réfugiés de la métropole de São 
Paulo. Dans ce travail, certains aspects de l'univers magico-religieux sont considérés comme essentiels à la compréhension des processus vécus sur le sol brésilien.

\title{
MOTS-CLÉS
}

Migration. Souffrance. Maladie. Sort.

\section{¿ENFERMEDAD O HECHIZO? EL FENÓMENO DEL "MALESTAR" Y LA EXPERIENCIA MIGRATORIA EN LA METRÓPOLI DE SÃO PAULO}

\begin{abstract}
RESUMEN
Este ensayo parte del informe etnográfico para desarrollar la reflexión sobre la experiencia de los inmigrantes negros, de origen haitiano, en São Paulo, problematizando las dinámicas sociales que involucran el manejo de la salud, la enfermedad y el sufrimiento en un contexto marcado por constantes transformaciones y intensos flujos globales de gente y conocimiento. El examen de esta compleja maraña de conexiones es objeto de investigación por parte del antropólogo que ha realizado trabajos de campo desde 2016 con la diáspora haitiana y las organizaciones que conforman la Red de Atención de Inmigrantes y Refugiados en la metrópoli de São Paulo. En este trabajo, los aspectos del universo mágico-religioso se toman como esenciales para la comprensión de los procesos vividos en suelo brasileño.
\end{abstract}

\section{PALABRAS CLAVE}

Migración. Sufrimiento. Enfermedad. Hechizo. 


\section{QUE TEM LÁ DENTRO ${ }^{1}$}

Olá! Bom dia senhora. Eu sou a esposa do Joseph D. Eu gostaria de entrar em contato contigo a respeito da morte dele, por favor, para eu saber o que está acontecendo.

[Hello! Bonjou madam. Mwen se madanm Joseph D. Mwen vle antre an kontak avèw osijè de lanmò a silvouplè poum kapab konnen sa kap fèt. $]^{2}$

Essa mensagem me foi deixada por Sylvie ${ }^{3}$, esposa de Joseph, quatro dias antes de realizarmos o seu enterro no dia 29 de outubro de 2017 em São Paulo. Acabávamos de encontrar o seu contato depois de uma busca que durou quase duas semanas e envolveu uma rede de amigos haitianos fora e dentro do Brasil ${ }^{4}$. Através de mensagens disparadas pelo Facebook, WhatsApp (redes sociais muito utilizadas entre a diáspora) e transmitidas pelas rádios haitianas online, conseguimos finalmente localizar a família de Joseph no Haiti. O primeiro contato foi com um conhecido, primo distante, que, morando no Canadá, ouviu a chamada na rádio e respondeu ao nosso apelo. Com a sua mediação, pudemos ligar para a família e comunicar sobre a sua morte. Quando faleceu, Joseph estava sozinho, morando nas ruas da capital paulistana, sem meios para se comunicar com a família que não tinha notícias do seu рагаdeiro há meses 5 .

Na nossa primeira conversa por telefone, Sylvie me escutava em silêncio. No entanto, a respiração ofegante e descompassada testemunhava a sua aflição. Eu expliquei quem eu era e como havia conhecido o seu marido. Lamentei pelo ocorrido e pela má notícia que trazia. Ela pediu detalhes sobre os planos para o funeral que infelizmente não poderia acompanhar.

Eu te liguei para saber como será o enterro dele. Você não nos disse como ele será feito, em que dia, que hora... Nós vamos te dizer a verdade, nós não

\footnotetext{
1 Uma versão preliminar deste texto foi lida no Seminário de Investigação Antropológica do Departamento de Antropologia do Instituto de Ciências Sociais da Universidade de Lisboa em dezembro de 2018. Agradeço os comentários dos professores Cristiana Bastos, Simone Frangella, Patrícia Ferraz de Matos e João Vasconcelos, assim como dos outros estudantes participantes do seminário, particularmente Rafael Agostini e Daniel Silva-Duarte, pelos valiosos comentários e sugestões.

${ }^{2}$ As conversas com os interlocutores haitianos foram mantidas originalmente em crioulo haitiano. As traduções dos trechos que aparecem neste artigo foram realizadas por mim.

${ }^{3}$ Os nomes que aparecem nesse trabalho foram todos alterados com a intenção de preservar as identidades dos interlocutores.

${ }^{4}$ Devo ressaltar o empenho do amigo antropólogo e comunicador social Behrman Garçon, de quem partiu a iniciativa por essa busca e a articulação com as mídias envolvidas. A ele sou grata por isso, e por tantas outras parcerias.

${ }^{5}$ Trago nesse ensaio, mais adiante, um breve relato sobre o encontro com Joseph e o impacto de sua história na trajetória da pesquisa de doutorado, em andamento.
} 
queríamos que o enterro dele fosse feito na nossa ausência. Mas, não podemos fazer nada (...) Ele está morto e me deixou com duas crianças para cuidar. Bom, eu não tenho recursos para ir ao funeral dele.

[Mwen te rele ou pou konne ki jan antèman an pral fè. Ou pa t di nou ki jan li pral fèt, ki jou epi ki lè... Nou pral di w verite, nou pa $t$ vle antèman an fèt nan absans nou. Men, nou pa ka fè anyen. (...) Mesye a fin mouri, li kite $m$ ak de timoun sou kont mwen. Bon, mwen pa gen mwayen pou m ale nan fineray li.]

Esclareci que ainda não sabia ao certo quando seria, pois os procedimentos burocráticos dependiam da presença de familiares. Eram os sobrinhos de Joseph que conseguimos localizar no Brasil que estavam tratando de autorizá-lo, naquele momento. Prometi tornar a ligar assim que tivesse outras informações. Ela, então, suspirou e insistiu para que eu desse uma explicação sobre o que havia realmente acontecido. Tudo aquilo parecia muito confuso - e, de fato, o era, para todos.

\begin{abstract}
Me dê uma resposta, senhora. Me diga o que aconteceu porque eu não sei de nada. Tem gente que me diz que ele estava em uma cirurgia a hora que ele morreu. Porque ele disse que deveria fazer uma cirurgia no coração. Porque quando ele chegou no Brasil disseram que ele tinha uma "bola" pequena no coração. Depois disso, ele começou a dizer que o que ele tinha era uma doença de feitiço, coisa de perseguição. Essa é a doença que ele tinha. No hospital, eles disseram que ele não tinha doença de coração nenhuma não. Tem gente que diz que ele estava na cirurgia do coração quando ele morreu, tem gente que diz que ele estava na rua e que um carro o atropelou. Mas, eu não sei o que tem lá dentro (no fundo, o que se passou). Amiga, você precisa nos explicar o que "fez" a sua morte.

[Ban mwen yon repons, madam. Di $m$ sa ki te pase paske mwen pa konnen anyen. Paske gen moun ki di $m$ ke se nan yon operasyon le li te mouri. Paske li te toujou di li gen pou l te fè yon operasyon nan kè. Paske lè li te rive nan Brezil, yo te di li te gen yon ti boul nan kè li. Apre sa, li te toujou di li gen yon maladi fetich, bagay pèsekisyon. Sa a se maladi a li genyen. Doktè toujou di ke li pa gen okenn maladi lopital. Gen moun ki di ke se te nan operasyon an li te mouri, gen lòt moun ki di ke li se nan lari a yon machin te frape l. Men, mwen pa konnen ki sa kit e pase, sa ki l'andedan. Zanmi, ou bezwen eksplike nou sa ki te fè lanmò li. $]^{6}$
\end{abstract}

Essa é uma pergunta para a qual eu não tinha uma resposta satisfatória. Sabia apenas que Joseph não havia sido submetido à tal cirurgia, apesar de ter sido prescrita medicação para o coração quando procurou o hospital pela primeira vez. A morte, segundo os médicos, teria sido causada pelo agravamento de seu quadro de saúde após ter sido vítima de um possível acidente ou agressão intencional. De acordo com os ferimentos encontrados (pernas e braços quebrados e um trauma na região da cabeça), duas eram as suspeitas: atropelamento e/ou espancamento. Ninguém podia afirmar, pois não havia testemunhas e, sem falar português, ainda que consciente quando socorrido, Joseph não

\footnotetext{
${ }^{6}$ Destaques feitos pelo autor.
} 
teve chances de apontar as razões do seu estado. Para além desse episódio, sobre o qual nada se sabe, a sua morte estava relacionada à uma trágica combinação de violações, descaso, abandono e negligência.

De fato, Sylvie estava segura de que sua morte não fora "natural". A cirurgia parecia improvável pois como ela mesma disse, quando ele retornava ao hospital não encontravam a tal "bola no coração", o que era uma forte evidência para a hipótese da maladi fetich (doença de feitiço). Era esse o mal declarado pelo próprio Joseph anteriormente, "coisa de perseguição". Quando ouviu de quem quer que seja - provavelmente de um dos parentes que estavam no Brasil - que ele teria morrido durante uma operação, ela desconfiara e, por isso, pedia a minha confirmação. Agoniada, Sylvie procurava respostas que dessem sentido aos acontecimentos passados e, também, àqueles que se desenrolavam no presente. Eu repeti o que havia escutado dos médicos e sem ter mais a elucidar, a nossa conversa naquele dia terminou.

Na tentativa de encontrar explicação às experiências que escapam ao seu controle, Sylvie mobiliza a potência de agências invisíveis, sobrenaturais, capazes de afetar profundamente a vida humana. Elemento que já figurava na própria narrativa de Joseph como presença marcante, pelo menos, no seu cotidiano recente. Ao fazer isso, sua intenção é desvendar as causas subjacentes aos males e sofrimentos que atingiram a vida de seu marido e acabaram por provocar a sua morte - nas suas próprias palavras: "o que tem lá dentro" e "o que fez a sua morte". Histórias, como a de Joseph, que enlaçam infortúnios, tais como a morte (lamò) e a doença (maladi), ao universo místico (mistik) da magia (maji) e do feitiço (fetich) não são incomuns entre meus interlocutores e aludem a muitas ocasiões que presenciei ao longo da minha trajetória de pesquisa com os haitianos, tanto no Brasil como no Haiti? ${ }^{7}$.

No início de 2013, enquanto eu realizava pesquisa de campo na Grand'Anse, investigando as práticas de ajuda mobilizadas após o terremoto de $2010^{8}$, o Haiti havia passado por uma epidemia de cólera sem precedentes que se alastrou por todo o país?

\footnotetext{
7 A pesquisa de doutoramento que venho desenvolvendo se baseia no trabalho de campo etnográfico em São Paulo, iniciado em 2016, mas se relaciona, de alguma maneira, com a trajetória prévia de pesquisa no Haiti, durante o mestrado, e de envolvimento com a comunidade haitiana, depois da volta ao Brasil. Durante dois anos, entre 2014 e 2016, dei aulas de português para haitianos recém-chegados em Campinas (SP) e pude acompanhar de perto a acomodação dessas pessoas. Muitos deles se tornaram amigos próximos, inevitavelmente.

${ }^{8}$ Esse trabalho deu origem a dissertação de mestrado "O (extra)ordinário da ajuda: histórias não contadas sobre desastre e generosidade na Grand'Anse, Haiti" (2015).

${ }^{9}$ A epidemia que eclodiu no país em novembro de 2010, tinha atingido 639.610 casos e 7.962 mortes em janeiro de 2013, de acordo com relatório do Ministério de Saúde Pública e da População (MSPP) do Haiti.
} 
Nesse período, entrei em contato, inúmeras vezes, com narrativas acerca do que eles chamavam "poud kolera": um pó fabricado de forma mágica a partir dos restos mortais de uma vítima da doença e capaz de espalhá-la, infectando aqueles que o tocasse ou ingerisse. Os rumores em torno do uso do pó inflamaram a população e provocaram linchamentos na região de Jérémie onde morei. As práticas "culturais" ordinárias, associadas ao vodu ${ }^{10}$ e a um conjunto de crenças e comportamentos bastante exotizados, foram apontadas, na época, como responsáveis pela propagação da epidemia.

Aquelas narrativas, associadas à ignorância e à irracionalidade na visão dos profissionais de saúde e da ajuda humanitária, eram manipuladas pela população local que não colocava em questão a existência da doença, mas procurava dar sentido à ocorrência inédita da epidemia, mobilizando acusações que envolviam a culpabilização de práticas religiosas associadas ao vodu condenadas pelas igrejas evangélicas, em ascensão no país, e as desconfianças em relação às ações das próprias organizações internacionais de ajuda humanitária, muito questionadas sobretudo no pós-terremoto. É importante ressaltar que, em tempos de crise, operações envolvendo rumores e acusações são recorrentes, não apenas no contexto haitiano, obviamente. As histórias que circulavam ali engendravam tensões bastante concretas, existentes na configuração complexa dos atores que atuavam naquele contexto e motivaram profundas reflexões durante a pesquisa que conduzi.

Mais recentemente, ao realizar pesquisa acerca da experiência migratória na cidade de São Paulo junto à comunidade haitiana - que começa a se estabelecer no Brasil sobretudo a partir de 2010 (FERNANDES et al, 2012; HANDERSON, 2015, 2017; BAENINGER et al, 2016; BERSANI; HANDERSON, 2017) - tenho me debruçado sobre trajetórias pessoais e histórias de sujeitos que repõem imbricamentos complexos entre expectativas e frustrações, sucessos e fracassos associados ao deslocamento. O desafio de narrá-las implica trazer à tona tipos densos de arranjos que desafiam o horizonte normativo e classificatório do campo da saúde, do direito, bem como das políticas públicas e serviços oferecidos para essa população ${ }^{11}$.

\footnotetext{
${ }^{10}$ Termo polissêmico que dá nome a um conjunto de práticas e crenças frequentemente associadas aos costumes dos povos da costa ocidental da África transportados para a América com os escravos entre os séculos XVI e XIX. "Também é comum que a palavra (vodu) seja associada à feitiçaria, à cultura popular do Haiti (seu folclore e suas artes) e à marronage, movimentos de fuga, resistência e luta pela liberdade dos escravos ao longo do processo que culminou com a independência do país em 1804" (DALMASO, 2018, p. 96). Sobre a antropologia e o seu investimento no estudo do vodu haitiano ver também Hurbon (2005) e Ramsey (2005).

${ }^{11}$ Sobre as lógicas de classificação articuladas no cenário brasileiro diante da recente chegada dos imigrantes haitianos, as políticas migratórias adotadas pelo Estado e a centralidade da categoria êmica diaspora para a compreensão da experiência haitiana, pude refletir no artigo "Chache lavi Deyò: uma reflexão sobre a categoria refúgio a partir da diáspora haitiana no Brasil", Cadernos de Campo, São Paulo, n. 25, p. 383-399, 2016.
} 
Apesar de se referirem a outros tipos de percalços, as situações etnográficas que tenho vivenciado junto à diaspora ${ }^{12}$ em São Paulo se relacionam com o problema colocado pelos rumores sobre a epidemia de cólera no Haiti, especialmente no que diz respeito às disputas em torno do estatuto de verdade que interpelam. A narrativa científica enquanto dispositivo discursivo da biomedicina, racional e legítima, é, nessa arena, preponderante e importante articuladora das dinâmicas de poder - as conhecidas biopolíticas sobre as quais nos ensinou Foucault $(1999,2008)$.

"Doença ou feitiço?" A pergunta retórica que dá título a este ensaio localiza-nos no trivial lugar de impasse que encontro em campo ao olhar para as aflições e os sofrimentos de muitas pessoas em suas trajetórias migratórias. Conjugando as abordagens da antropologia da saúde e da religião, pretendo explorar aqui a potencialidade do trabalho etnográfico para a reflexão acerca do tema migratório, a partir de uma perspectiva que extrapole as dicotomias entre ciência e religião, medicina e cultura ou corpo e espírito, por exemplo. Mais do que averiguar a veracidade das narrativas, ou arbitrar acerca da racionalidade que as sustenta, reforçando discursos que polarizam superficialmente os atores, os saberes e as práticas, o meu intento é aproximar-me da experiência vivida, em termos fenomenológicos.

Ao antropólogo, interessa a articulação das diversas lógicas sociais que interagem se complementam e se confrontam - dando sentido aos acontecimentos e fundamentando as razões que organizam cada realidade. Nesse sentido, a compreensão das narrativas êmicas e dos seus significados, para além da dimensão metafórica, é fundamental. Levar a sério o que os haitianos dizem implica considerar o universo da maji (magia) enquanto dimensão vitalmente relevante da experiência migratória que interage também com as possibilidades de engajamento face ao sofrimento. Assim como faz o antropólogo Ramon Sarró em um inspirador relato sobre a diáspora africana e as narrativas em torno do roubo de órgãos e do medo dos hospitais em Lisboa, busco desenvolver uma etnografia centrada nas pessoas, seus medos e expectativas, mostrando que "também nas coisas mais improváveis há muito de verdade" (2007, p.328).

O relato que abre esse texto é parte de um encontro que impactou a tessitura do próprio objeto de análise da pesquisa que foi sendo construída ao longo desses últimos anos. De forma particularmente trágica, a trajetória de Joseph revelou a estreita relação entre a experiência migratória e o adoecimento, algo que já havia chamado a minha atenção quando cruzei com outras histórias de sujeitos que tive a oportunidade de acompanhar como

\footnotetext{
12 Sobre a categoria êmica diaspora (grafada sem acentuação, de forma a corresponder com o crioulo haitiano, e em itálico nesse artigo), ver Handerson, 2015b, p. 51-78, e Richman, 2005. Esclareço ainda que quando usada enquanto conceito analítico mais abrangente para designar o conjunto de pessoas de origem haitiana dispersas pelo mundo utilizarei a palavra diáspora, acentuada.
} 
intérprete nas consultas psiquiátricas ou nos outros diversos serviços e tratamentos que lhes foram oferecidos, e como amiga, na luta cotidiana que travam para habitar a grande metrópole paulistana.

Nas linhas que se seguem, e a partir do caso em questão, refletirei sobre como as ideias de precariedade, crise, desconforto e sofrimento se associam e são associadas à experiência migratória constituindo o que passo a chamar de fenômeno do "mal-estar"13. Tendo em vista os diferentes contextos em que essa relação se impõe, interessa-me analisar as circunstâncias nas quais tal fenômeno emerge, paralelamente à proeminência que ganha o campo da saúde junto à questão migratória no espaço urbano metropolitano marcado por graves contrastes sociais.

Há, sem dúvida, neste cenário, um manifesto paradoxo, já explorado por Didier Fassin (2012) ao analisar as políticas migratórias contemporâneas: o aumento da oferta de "cuidado" de forma concomitante ao controle da mobilidade e a negação de direitos sociais e políticos aos deslocados. A complexa dinâmica de conjecturas e acusações em torno da doença e da morte em deslocamento - que escapa ao olhar mais especializado dos médicos e profissionais que atuam na atenção a essa população, incluindo os especialistas em migração - expõe as fragilidades das relações ali colocadas. O universo da maji (magia), tido enquanto dimensão mais oculta, obscura e duvidosa dessa experiência, é, ao contrário, uma lente indispensável para a compreensão de tal contexto e de suas ambivalências.

\title{
UM CASO DELICADO: ENTRE A SAÚdE, O CUIDADO E A VIOLÊNCIA
}

Era uma tarde de quarta-feira, setembro de 2017. Recebi uma ligação da então coordenadora do Centro de Referência e Atendimento para Imigrantes de São Paulo $(\text { CRAI })^{14}$. A Marcela, que já havia se tornado uma amiga, naquela altura, estava aflita e pedia a minha ajuda para cuidar de um caso, nas suas próprias palavras, "bem delicado".

\begin{abstract}
${ }^{13}$ Fazendo uma espécie de jogo com o conhecido uso da ideia de mal-estar feito por Freud (1996 [1929]) em relação à problemática da civilização, neste trabalho, ao empregar a palavra "mal-estar", procuro designar toda uma gama de modalidades distintas de vivenciar e interpretar o sofrimento. Apesar de não me apropriar do conceito freudiano tal qual este é acionado para abordar o mal-estar que assola os indivíduos em sua vida civilizada, ele me parece útil para escapar das classificações estanques conferidas a estados psíquicos e processos patológicos (codificados sob formas jurídicas, morais ou clínicas) e apontar para a relação destas com uma determinada época e contexto. O que interessa aqui são os sentidos da experiência de sofrimento que emergem da relação contingente entre os sujeitos e o social, e da relação estabelecida entre ela e o deslocamento. Assim, considero "mal-estar" tudo aquilo que expressa, entre os espaços culturais, a área das "perturbações", todas as categorias através das quais se designam os sinais do que "não vai bem" com as pessoas e que, portanto, abarcam quase toda a gama de problemas, dores, doenças e distúrbios que acometem um sujeito.
\end{abstract}

${ }^{14}$ Equipamento público municipal de referência na atenção especializada à população imigrante em São Paulo, criado em novembro de 2014 - no auge da chegada dos haitianos na cidade - com o 
Ela começou, então, a descrever a situação da seguinte maneira: havia um senhor de origem haitiana que estava doente em um hospital no Tatuapé, na zona Leste da cidade de São Paulo, e o problema parecia estar relacionado a dificuldade de comunicação com ele. De acordo com a assistente social do hospital, ele "normalmente" falava português, mas provavelmente, em razão da doença, do cansaço e da idade, estaria com dificuldades de se exprimir. Essa queixa chegou até eles pois os médicos e outros profissionais de saúde do hospital desconfiavam que ele estivesse manipulando-os para não deixar o local, uma vez que já havia recebido alta e seguindo as determinações hospitalares não deveria mais estar ocupando aquela "vaga". Segundo eles, o senhor "fingiria" não entender quando eles propunham que ele fosse embora e se negava a sair. Ele encontrava-se ali há pelo menos dois dias. A assistente social estava preocupada. Os médicos estavam irritados e teriam ameaçado chamar a polícia para tirá-lo à força de lá, se necessário fosse. Marcela me explicou que era compreensivel que ele quisesse permanecer no hospital, pois talvez se sentisse mais seguro e cuidado ali.

A ajuda que eu poderia prestar seria, portanto, tentar convencê-lo a deixar o hospital e ir para um Centro de Acolhida da rede de assistência municipal, onde supostamente haveria uma vaga para acolhê-lo. Da sua perspectiva, eu teria mais condições de fazer isso já que poderia conversar com ele em sua língua materna, o crioulo haitiano15, e perceber o que estava "realmente" acontecendo. A situação era grave e havia uma certa urgência diante da ameaça dos médicos. Eu aceitei ir até lá para ajudá-los. Combinamos, então, e, no dia seguinte pela manhã, fomos as duas até o hospital.

Logo na chegada, nos deparamos com uma cena bastante comum nos hospitais públicos brasileiros: os corredores abarrotados de pacientes e macas por todos os lados. $O$ serviço estava visivelmente funcionando no limite da sua capacidade. Apesar do caos aparente, entramos facilmente com as credenciais do CRAI e não foi difícil reconhecer Joseph sentado em uma cadeira na ala de emergências. Um senhor negro, com o cabelo sem corte e a barba não aparada, um pouco grisalha (talvez por isso a descrição que fizeram sobre ele ser um senhor idoso, o que não correspondia com a sua idade. Ele tinha apenas 51 anos). Os seus únicos pertences estavam em uma sacola plástica no chão ao lado da cadeira em que se sentava. Em uma das mãos, segurava uma radiografia e o resultado de alguns exames.

objetivo de promover o acesso a direitos e a inclusão social, cultural e econômica das pessoas migrantes no município.

15 O crioulo haitiano é a única língua falada por todos no Haiti, que tem também o francês como língua oficial. No contexto brasileiro, no entanto, é raro encontrar falantes de crioulo nos espaços e serviços públicos em geral, dado importante para se compreender as questões relacionadas ao acesso dos sujeitos migrantes, a sua integração e as dificuldades que encontram ao percorrer os caminhos institucionais e/ou burocráticos. 
Tinha os pés inchados em um par de sapatos que ele não podia atar, pois já não encaixavam. Ele tinha o ar cansado e já sem paciência.

Enquanto a Marcela perguntava pela assistente social no balcão da enfermagem, eu me aproximei, sentei-me ao seu lado e perguntei o seu nome, falando em crioulo. Disse que eu era brasileira, mas podia falar a sua língua pois tinha morado no Haiti. Os seus olhos brilharam ao me encarar. Ele estava surpreso, reação que se tornou corriqueira a cada vez que eu, sendo branca, abordava os imigrantes em crioulo em solo brasileiro. Ele me disse seu nome e também que tinha sede. Eu fui até a enfermeira que estava atrás do balcão e descobri que o hospital estava racionando a água para os pacientes pois, segundo ela, estava em falta. Como se abrisse uma exceção, ela me entregou um copo plástico com um pouco de água e eu levei até ele. Joseph tinha um pedaço de bolo embrulhado em um guardanapo nas mãos. Enquanto pegava as migalhas que iam se soltando, me disse que aquilo seria tudo que ele tinha recebido para comer nos últimos dois dias.

Naquele momento, eu tinha entendido, sem necessidade de maiores constatações, que estar ali não era uma vontade ou um desejo, muito menos que ele se sentisse protegido ou cuidado no hospital. Depois de perguntar como ele se sentia e escutar sobre um problema que tinha no coração, aquilo que o teria levado até lá, introduzi a pergunta: qual seria a razão de ele não querer deixar o hospital se já havia sido liberado pelos médicos? Ele riu, e disse que sua irmã estava ali, bem próximo, na outra sala. Disse que eu logo a veria, se aguardasse um pouco. Ele não poderia sair dali sem ela. Eu fiquei confusa e perguntei à Marcela sobre alguém da família que pudesse tê-lo acompanhado. A assistente social disse que não havia ninguém.

Continuamos a conversa. Joseph me garantiu que não tinha se recusado a sair. Ele parecia não ter percebido que não poderia ficar ali. A única razão do desentendimento com os enfermeiros, segundo ele, era o fato de não terem deixado que ele bebesse água. Sim, ele estava bastante irritado com eles. Enquanto eu assegurava que ele poderia confiar em nós e que tínhamos um lugar, "uma nova casa para levá-lo", ele me falava sobre sua irmã e um sobrinho que deveriam aparecer a qualquer momento.

Joseph articulava as frases de uma forma um tanto quanto confusa e eu me esforçava para perceber o que ele dizia. Ele me olhava com afeição e não se incomodava em repetir aquilo que eu não conseguia decifrar, por vezes seguidas até que estivesse mais claro. Acolhia o que eu dizia e em nenhum momento resistiu a ideia de ir para um outro lugar. Ele estava claramente confuso e desorientado. Enquanto me contava sobre Bahamas, piscou os olhos para alguém que eu não podia ver e que ele garantia ser o sobrinho passando no corredor ao lado. Sobre a sua história, nada sabíamos. Ele não tinha os documentos consigo, nem telefone celular. Disse ter sido roubado. Não sabia nos informar o contato de um familiar, mas disse o nome da irmã a qual aguardava: Nouze. Eu anotei e prometi que 
procuraríamos por ela. Enquanto isso, Marcela que tentava articular a vaga no Centro de Acolhida se aproxima para dar-nos a notícia de que precisaríamos aguardar até o dia seguinte para levá-lo até lá. Combinamos que voltaríamos. Ele segurou as minhas mãos e disse que esperaria.

Saímos do hospital abatidas, sabendo que ele passaria mais uma noite sentado em uma cadeira naquele corredor agitado e inóspito. Também nos preocupava o fato de ele não estar tomando a medicação receitada para a doença no coração, mais um item que estava em falta e o hospital não podia oferecer. Na sexta-feira, no início da tarde, assim que a Marcela teve a confirmação da vaga e da ambulância que nos levaria para lá, seguimos apressadas para o Tatuapé. Joseph sorriu contente quando nos viu. Com alguma dificuldade, ele caminhou até a ambulância que já nos aguardava. Ele foi deitado e eu fui sentada bem ao seu lado. Ele dormiu por alguns minutos enquanto atravessávamos a cidade através do trânsito intenso até o distrito do Bom Retiro, região central da capital. Logo que chegamos ao Centro de Acolhida, Joseph abriu os olhos e eu disse: "Chegamos em casa". Confuso, ele me perguntou: "Nós já estamos no Haiti?"

Apesar da alta e do fato da enfermidade específica relacionada ao funcionamento do coração não ter figurado entre as principais preocupações do pessoal do hospital, Joseph estava visivelmente debilitado e precisava de cuidados mais permanentes. Infelizmente, a ida para o Centro de Acolhida no Bom Retiro era uma medida paliativa. Ele não poderia ficar ali pelo tempo necessário e nem contar com o acompanhamento de profissionais de saúde nesse serviço. A Marcela se comprometeu a lutar por uma vaga em um Centro de Acolhida para pessoas convalescentes onde teriam uma maior estrutura para a atenção continuada e para o acompanhamento psicológico. Essas vagas são raríssimas na cidade e enquanto isso ele ficaria ali, vivendo com outros desabrigados que a cada semana precisavam renovar o pedido da estadia. Depois de mobilizar a Secretaria de Assistência Social através da Coordenadoria de Políticas para Migrantes da Secretaria Municipal de Direitos Humanos, o CRAl conseguiu a vaga e, na segunda-feira, recebi a informação de que o Joseph poderia ser transferido no dia seguinte. Na terça-feira, portanto, fomos até lá a sua procura, mas para a nossa surpresa não o encontramos.

Um dos funcionários do Centro de Acolhida que estava na recepção naquele momento nos disse que ele havia saído na noite anterior depois de ter recebido uma repreensão devido a um comportamento considerado inapropriado e não teria voltado, desde então. Apesar de saberem da transferência agendada, os funcionários não se importaram quando ele saiu pois diziam que não era parte das suas funções controlar a entrada e saída dos usuários. Ele contou que os outros conviventes haviam reclamado de Joseph. Ele teria urinado em local inapropriado no banheiro. Um dos funcionários acrescentou ainda: "Ele precisa aprender e cumprir as regras se quiser ficar aqui". Saímos 
para procurar por ele, pelas redondezas. Imaginei que ele não pudesse ter chegado muito longe, nas condições em que se encontrava. Mas não o encontramos.

Perdemos o Joseph de vista. Ele nunca mais voltou para a Centro de Acolhida. Mas foi encontrado na rua, naquela mesma região, alguns dias mais tarde e levado para um Pronto Socorro, dessa vez na Zona Norte, em Santana. Essa informação chegou até nós no dia 6 de outubro, mais ou menos quinze dias depois da última vez que nos vimos. Ele carregava um cartão no bolso que continha o logo do Centro de Acolhida estampado, o que permitiu que no Pronto Socorro ligassem para saber mais informações sobre ele.

Seu estado era gravíssimo, ele tinha sofrido fraturas nos dois braços e em uma das pernas, além de um trauma na região da cabeça. A principal suspeita era de um espancamento. Também nos falaram sobre um possível atropelamento. No Pronto Socorro aguardavam uma vaga em uma Unidade de Terapia Intensiva para transferi-lo para um hospital. Os dias se passaram e, sem ter tido garantido o atendimento de que necessitava, Joseph entrou em coma e estava entubado. Assim que soube, fui até lá acompanhada de um dos funcionários do CRAl, encaminhado pela Marcela. Mais uma vez, não o encontramos. Ele havia sido transferido no meio da noite para o hospital do Mandaqui, um dos maiores hospitais públicos da cidade, localizado na mesma região. Pudemos conversar com o assistente social que confirmou a suspeita de que o agravamento do seu quadro teria ocorrido pela falta de atendimento adequado. Segundo ele, os médicos queriam que Joseph deixasse o Pronto Socorro e se irritavam pois ele não tinha uma família para buscá-lo e não conseguia caminhar com as dores que sentia na perna. Alguns dias mais tarde, uma radiografia comprovou que a perna estava fraturada. O tempo que ele passou ali inassistido fez com que o seu quadro de saúde piorasse. Enfisema pulmonar é a doença que aparece como causa da sua morte, no documento que a atesta.

Tive a oportunidade de estar com Joseph pela última vez naquele mesmo dia na sala de emergências do Mandaqui. Apesar de ter sido transferido, ele nunca havia conseguido a vaga na UTI. Os enfermeiros que trabalhavam ali pareceram surpresos quando chegamos para vê-lo. Todos sabiam que ele não resistiria. Um deles se aproximou e perguntou se poderíamos ficar com os seus sapatos. De pé, ao lado da maca em que se encontrava, eu falei com ele. Sem saber o que dizer, falei sobre o Haiti em crioulo. Imediatamente, os batimentos cardíacos se alteraram. Fomos retirados da sala. Dois dias depois, no dia 14 de outubro, ele faleceu. A sua morte inaugurou um outro capítulo dessa história, uma aventura em busca da sua família em conjunto com outros amigos haitianos e da tentativa de reconstruir partes da sua história ${ }^{16}$. Joseph foi enterrado no dia 29 de outubro, seis dias depois de termos encontrado seus sobrinhos que ainda residiam no Brasil.

${ }^{16} \mathrm{O}$ pessoal do CRAl iniciou um trabalho conjunto de reunião de documentos e escrita de um relatório a ser encaminhado para a ouvidoria da secretaria de direitos humanos, exigindo que as 
Esse foi um dos "casos delicados" que cruzaram o meu caminho ao longo da pesquisa e, apesar de não constituir um exemplo generalizável para todos os outros haitianos que vivem na cidade de São Paulo atualmente ${ }^{17}$, compõe um eloquente conjunto de experiências que julguei precisarem ser analisadas com cautela. As tensões, violências e desigualdades sociais profundas que enlaçam essa história, dizem muito sobre as condições da experiência migratória e sobre a sua associação às ideias de escassez e sofrimento. Manifesto de forma dramática no caso de Joseph, o "mal-estar" em deslocamento parecia ser, no entanto, parte do cotidiano dos meus interlocutores, articulado genericamente através de uma expressão amplamente utilizada entre os imigrantes: "pase mizè" (passar miséria).

\section{DO PASE MIZĖAO "MAL-ESTAR" ENQUANTO PISTA ETNOGRÁFICA}

Em 2016, me mudei para São Paulo com a intenção de acompanhar o desdobrar de uma situação de "crise migratória"18 que havia sido alardeada no país após a chegada dos haitianos - evento que marcou uma nova fase da migração nacional, em um período de aumento considerável do número de recém-chegados e de uma inegável mudança no perfil dessa população (PATARRA, 2012; CAVALCANTI, 2016). Ao longo da última década, a chegada de senegaleses, angolanos, congoleses, venezuelanos e haitianos se somou à de bolivianos e peruanos, reforçando uma configuração na cena migratória completamente oposta aos pressupostos que elegeram, no passado, o branco europeu como modelo do "imigrante desejável" no país (AZEVEDO, 1987; SEYFERTH, 2002).

A cidade de São Paulo é o principal polo de recepção de trabalhadores internacionais e desempenha um papel importante enquanto locus de interação e troca

evidências de maus tratos e abandono fossem apuradas com seriedade. Não tenho notícias dos possíveis resultados desse movimento, uma vez que, com a mudança da gestão da prefeitura da cidade, várias outras alterações internas se seguiram. Além disso, pouco tempo depois toda a equipe do CRAI foi alterada dificultando o acompanhamento dos desdobramentos desse caso.

${ }^{17}$ De acordo com os dados da Polícia Federal, cerca de 73 mil imigrantes haitianos passaram pelo Brasil entre os anos de 2010 e 2016. A maior parte dos imigrantes fixou-se na Região Sul e Sudeste do país. No período entre os anos 2000 e 2016, cerca de 22.000 imigrantes haitianos haviam se registrado como residentes no Estado de São Paulo no Sistema Nacional de Cadastros e Registros de Estrangeiros (SINCRE). A região metropolitana de São Paulo destaca-se como principal locus dessa residência, chegando a registrar 13.465 imigrantes para o mesmo período. Sabemos, no entanto, que esse número é subestimado já que os dados contemplam apenas os imigrantes internacionais com Registro Nacional de Estrangeiro (RNE), deixando os indocumentados e solicitantes de refúgio de fora. (Fonte: OBMigra- Ministério do Trabalho. Observatório das Migrações em São Paulo - NEPO/UNICAMP-Fapesp/CNPq.)

${ }^{18}$ Para uma reflexão sobre as tensões entre direitos humanos e securitização implícitas à ideia de crise migratória e a relação entre as políticas globais da atualidade e a formulação de políticas públicas migratórias e de controle de fronteiras no Brasil, ver Feldman, 2018. 
entre essas comunidades. Ao longo dos últimos anos, o espaço urbano foi sendo visivelmente tomado por essa presença. Nesse cenário, em meio a episódios cotidianos de xenofobia, racismo e violência, essa população ia se instalando. Me interessava acompanhar aquela dinâmica de perto, além de seguir, também, os novos desenhos que iam se traçando nas políticas públicas municipais - o que incluía, por exemplo, a criação da Coordenadoria de Políticas para Migrantes (CPMig) no âmbito da Secretaria Municipal de Direitos Humanos e Cidadania de São Paulo, em maio de 2013, e do Centro de Referência e Atendimento para Imigrantes (CRAI), serviço embasado e sustentado pela aprovação da Lei Municipal n 16.478, sancionada no dia 7 de julho de 2016, instituindo diretrizes para a políticas públicas aos imigrantes em âmbito municipal.

A minha entrada em campo se deu em razão, e a partir, dos imigrantes haitianos. O conhecimento sobre história e cultura haitianas, e sobretudo a fluência na língua crioula, me conferia o status de "expert" em meio à existência de um profundo desconhecimento sobre esses sujeitos e sobre as dinâmicas migratórias em questão. Comecei a circular como antropóloga, militante pelos direitos migratórios - na luta pela nova lei migratória federal que foi aprovada em novembro de 2017 -, apoiadora de lideranças imigrantes e colaboradora de associações, organizações não governamentais e de alguns serviços públicos municipais, como o CRAl. Também atuei como intérprete e mediadora nas situações mais diversas, sobretudo nos serviços de saúde. Passei a fazer parte da "Rede de cuidados aos imigrantes e refugiados", um grupo de pessoas (profissionais da saúde, assistentes sociais, religiosos, antropólogos, imigrantes, refugiados, ativistas) que se reúnem uma vez por mês para falar sobre os desafios do "cuidado" à população migrante e para partilhar experiências. Esse circuito tornou-se parte do que eu entendi como sendo meu "campo de pesquisa"19.

As reflexões levadas a cabo durante aquele primeiro momento de trabalho de campo (entre os anos de 2016 e 2017), a partir da percepção empírica da relevância do tema da saúde e do acompanhamento ativo de "casos delicados" como o de Joseph, sustentaram um desenho de pesquisa já mais delimitado. A proposta de estudo etnográfico que comecei a desenvolver visava descrever a articulação das diferentes lógicas sociais colocadas em jogo em torno do que chamei fenômeno do "mal-estar", parte inegavelmente relevante do cotidiano e da experiência migratória nesse contexto.

O primeiro movimento nesse sentido foi me debruçar sobre a pergunta: Como é que se tem vivenciado o deslocamento para o Brasil, no geral, e, mais especificamente, a acomodação em São Paulo? Essa pergunta opera um deslocamento para a dimensão cotidiana, mais complexa, interseccional e de forte agência dos sujeitos na operação de

\footnotetext{
${ }^{19}$ Parto do princípio de que em antropologia, o "campo", objeto de pesquisa final, não é apenas onde vamos realizar a investigação, mas é, sobretudo, algo que construímos ao mesmo tempo que analisamos.
} 
cálculos, negociações e na criação de estratégias de resistência, trazendo para o plano da experiência a compreensão dos fenômenos de escala sociológica maior. É importante ressaltar que esse recorte vai na contramão do que se têm priorizado nas pesquisas produzidas sobre o contexto migratório nacional que enfatizam sobretudo as dimensões quantitativas e demográficas e as áreas do trabalho e do direito para se pensar sobre o deslocamento e a acomodação dos sujeitos ${ }^{20}$.

O interesse em captar aquilo que escapa simultaneamente aos especialistas em migração e ao universo das instituições fez com que eu me dedicasse a realizar uma etnografia em movimento, circulando entre a rede de cuidados e a diáspora haitiana na cidade de São Paulo. Foi assim que o "mal-estar" se impôs enquanto problema etnográfico. Essa ideia passou a funcionar como um dispositivo que permite expandir o olhar, considerando as distintas formas de vivenciar e interpretar o sofrimento, além da relação estabelecida entre ele e o deslocamento. Tal dispositivo é tomado de modo a evitar o risco da substancialização ou literalização de uma definição estanque do mal, deixando essa categoria fluida, passível de ser mobilizada por diferentes atores, a partir de múltiplos referenciais. Assim, pode-se considerar tudo aquilo que expressa, entre os espaços culturais, a área das "perturbações", todas as categorias através das quais se designam os sinais do que "não vai bem" com as pessoas e que, portanto, abarcam quase toda gama de problemas, dores, doenças e distúrbios que acometem um sujeito.

Apesar de aparecer de distintas formas, a estreita relação entre a experiência de deslocamento e as ideias de precariedade, crise, desconforto e sofrimento constitui uma impressão compartilhada entre meus interlocutores. Circular pela "Rede de cuidados" me permitiu olhar para esse emaranhado de conexões a partir de um ponto de vista privilegiado. Resolvi, então, tomar essa relação como pista etnográfica a ser seguida, explorando sua potencialidade tanto em termos teóricos como analíticos.

A centralidade do campo da saúde que pude constatar, enquanto espaço de discussão e articulação entre ativistas, lideranças imigrantes, membros do governo municipal, associações religiosas e organizações não governamentais não é algo trivial. A saúde é percebida enquanto demanda e elemento fundamental no processo de integração das pessoas na sociedade, mas, mais do que isso, neste contexto, ela representa a possibilidade de garantia de direitos à população migrante. Na tentativa de assegurá-los, através de uma interessante articulação com a ideia de "cuidado", o campo da saúde aparece enquanto caminho viável nessa direção. Tal equação exige, no entanto, uma operação de

20 Ver como exemplo o conteúdo da coletânea "Imigração haitiana no Brasil" (BAENINGER, R.; PERES, R.; FERNANDES, D.; SILVA, S. et al., 2016). 
aproximação entre a condição de migrante/refugiado à de sofrimento, mais especificamente, de sofrimento psíquico.

Nesse sentido, a proliferação de serviços de cuidado em saúde mental que passam a ser oferecidos para essa população na cidade pode ser compreendida em uma chave mais complexa do que aquela que limitaria esse movimento à patologização da experiência migratória, por exemplo. Apesar de estarem convencidos acerca da necessidade de oferecer o "cuidado", há, no entanto, um declarado embaraço por parte dos atores atuantes nessas organizações e serviços quando eles se defrontam com a multiplicidade de interpretações e formas de interação com os males físico-morais (DUARTE, 1988, 1994) que afligem essas pessoas.

A insuficiência simbólica para se pensar sobre "o que é da cultura deles" a partir da biomedicina e do modelo da pessoa cindida moderna (SARTI, 2010, p.83) não é novidade e inquieta. A "cultura" aparece, ao lado da língua, enquanto barreira, tanto para o acesso, como para a adesão aos tratamentos propostos. Dessa forma, as ações postas em prática pelos médicos, psicólogos e profissionais da saúde são desafiadas já que a tentativa de endereçar o sofrimento vivido pelos imigrantes, qualificando-o enquanto distúrbio psíquico, parece muitas vezes não ser completamente bem-sucedida. Os diagnósticos frequentemente não ressoam nas experiências dos próprios sujeitos implicados nos tratamentos, que interagem com os acontecimentos a partir de outras gramáticas e visão de mundo. A saúde mental e as várias terapêuticas psi, incluindo a clínica transcultural e a etnopsiquiatria ${ }^{21}$, não são, via de regra, demandas trazidas pelos próprios imigrantes.

O desconforto gerado no contato/confronto com imaginários alternativos de construção do Mundo e da Pessoa informa também o meu lugar em campo e o interesse pelo fazer antropológico enquanto competência desejável nesse circuito. Como uma espécie de tradutor/mediador, o antropólogo é convocado enquanto profissional capaz de traduzir a "cultura do outro" e negociar com ela, neutralizando as barreiras do entendimento entre as partes. Esse é um aspecto importante que não poderei desenvolver nesse trabalho, mas que compõe parte das reflexões desencadeadas pela pesquisa como um todo.

Levar a sério o desconforto e a insatisfação dos profissionais atuantes nos serviços que compõem a Rede, de maneira geral, problematizando as práticas e posturas adotadas não significa negar, ao mesmo tempo, o desconforto, "mal-estar", vivenciado pela população migrante, algo que pude constatar na interação constante com a comunidade haitiana em diáspora. É nesse sentido que trajetórias como a de Joseph, apesar de singulares, nos fornecem material privilegiado para a compreensão dos sentidos da articulação entre a experiência migratória - enquanto espaço onde se ordenam novas possibilidades de se

\footnotetext{
${ }^{21}$ A esse respeito ver respectivamente Moro (2015) e Nathan (1986).
} 
pensar o mundo e a si próprio -, o "mal-estar" e os múltiplos recursos mobilizados para se lidar com ele. Para tanto é preciso situar os fenômenos da doença-dor-sofrimento no contexto social que thes dá sentido, um sentido sempre relativo.

Ao invés de centrar atenção nas "barreiras culturais e linguísticas" que dificultam o acesso à saúde, o meu interesse em abordá-las é, justamente, a gramática cultural em operação, o modo de perceber, viver e lidar com as incertezas, privações e o sofrimento. Tomar o "mal-estar" enquanto fenômeno, campo privilegiado de observação, significa, também, atentar para a potencialidade dos efeitos das relações produzidas em torno dessa questão, inclusive, dentro do campo da saúde. Enquanto elemento catalizador de tensões, capaz de articular sistemas culturais e formas simbólicas distintas, a dinâmica da negociação dos diferentes saberes, estratégias e práticas dos atores nela envolvidos tornou-se especialmente interessante.

A partir de uma perspectiva que radicaliza o caráter produtivo dos deslocamentos humanos, a "cultura" não é considerada problema a ser ultrapassado, mas elemento chave da experiência. Contrariando a visão caricatural que encapsula as narrativas, crenças e práticas culturais às ideias de inverdade, superstição e ignorância - coisa fechada contrária às inovações e avessa à medicina hegemônica -, interessa-me tomá-las enquanto articuladoras das relações, dinâmicas e processos sociais e políticos mais vastos. As narrativas acerca do "mal-estar" iluminam, assim, as contradições presentes na própria sociedade brasileira e colocam em causa oposições e hierarquias estanques ou inequívocas.

\section{MALADI FETICH, A EXPERIÊNCIA E O SOCIAL}

Joseph nasceu em Artebonite, província haitiana. Ele era casado e pai de dois filhos. Em 2017, ano de seu falecimento, o mais novo estava com cinco e o mais velho com oito anos de idade. Antes de deixar o Haiti, ele morava com sua esposa e filhos em Porto Príncipe, capital do país. No ano de 2012, pouco tempo após casar-se com Sylvie, ele parte rumo ao Brasil pela primeira vez. Na época, eles já tinham o primeiro filho e ele migrava com a intenção de garantir melhores condições de vida para a família, ou melhor, para chache lavi deyò (buscar a vida fora) - expressão amplamente utilizada em crioulo para se referir ao movimento diaspórico, fenômeno antigo e estrutural da dinâmica social haitiana. Antes do Brasil, Joseph já havia trabalhado por alguns anos na construção civil, no arquipélago caribenho das Bahamas, indo e vindo para casa sempre que podia. Não podendo habitar a sua terra, sua existência (desterrada) tinha no movimento o seu lugar de ser. Ele fazia parte daquele primeiro fluxo de imigrantes haitianos que chegaram no Brasil atraídos pelas oportunidades que esse país passou a representar no contexto do pós-terremoto enquanto 
um novo espaço estratégico, seja como rota migratória ou como destino na busca incessante pela vida melhor.

Depois de um longo trajeto, passando pela República Dominicana, Equador, Peru, norte do Brasil (pela cidade de Tabatinga, na tríplice fronteira entre Colômbia, Peru e Brasil), Joseph chega a Caxias do Sul, onde foi rapidamente empregado e absorvido pelo trabalho na indústria de suinicultura (produção de carne de porco), junto com outros de seus compatriotas. Naquele momento a rota predominante era a entrada pela fronteira terrestre ao norte, onde se fazia a solicitação de refúgio necessária para se permanecer no país. Em posse do protocolo que atestava a solicitação, os imigrantes entravam com o pedido dos documentos de identificação nacional (CPF e carteira de trabalho) para finalmente seguir viagem rumo às regiões sul e sudeste, mais ricas e demandantes de mão de obra, sobretudo para as funções mais estafantes e mal remuneradas.

Depois de alguns meses ele adoeceu. De acordo com Sylvie, que concordou em me contar mais sobre a vida daquele que conheci já em seus últimos dias, ele havia sido diagnosticado com um problema no coração que o impedia de trabalhar. O diagnóstico médico, porém, nunca se confirmara e ele afirmava que a causa do seu adoecimento seria uma maladi fetich (doença de feitiço), uma perseguição. Em busca de cura, ele voltou ao Haiti e passou alguns meses na terra natal de sua mãe, em uma pequena comunidade rural chamada Verrete. Joseph buscou tratamento com um doktè fèy (curandeiro; na tradução literal, doutor ou médico de folhas).

Foi nesse período que Sylvie engravidou do segundo filho dos dois. Em 2013, acreditando estar curado, Joseph volta ao Brasil, dessa vez vai para Itaquera, na zona leste de São Paulo, onde consegue trabalho em uma fábrica de persianas e participa da construção do Itaquerão, estádio do Corinthians erguido nas vésperas da Copa do Mundo de futebol masculino de 2014. Apesar do esforço em manter a vida em movimento, ele perde o emprego outra vez. Sem ter como se sustentar, passa a morar com a irmã Nouze em Guaianases, no extremo leste da cidade. Em 2016, porém, a crise econômica chega de forma mais drástica ao Brasil e os empregos ficam cada vez mais escassos. Diante das dificuldades, Nouze decide voltar para o Haiti. Joseph fica e, em busca de ajuda, procura um dos seus dois sobrinhos que também haviam permanecido no Brasil. Ele passa algum tempo na casa de um deles, mas se vê obrigado a sair de lá quando o relacionamento com a esposa do sobrinho se complica. Nada me foi dito sobre as razões do desentendimento, mas as brigas e discussões teriam se tornado constantes, inviabilizando a sua permanência na casa.

Essas são conjecturas feitas por mim a partir dos fragmentos das conversas que presenciei e da inegável tensão em torno das acusações de abandono que a família no Haiti lançava contra os sobrinhos que permaneceram no Brasil. A verdade é que quase nada eu consegui saber sobre o que veio a acontecer com ele entre a saída da casa do sobrinho até o 
nosso primeiro encontro no hospital do Tatuapé, em setembro de 2017. Nem mesmo Sylvie sabia detalhes do seu percurso. Ele já estava há algum tempo sem dar notícias ou enviar ajuda - em forma de remessas - para os filhos no Haiti. Nenhum outro familiar sabia precisar o seu paradeiro. Havia apenas uma coisa sobre a qual todos concordavam: ele estava doente, doença de perseguição, maladi fetich. Um mal que veio a acometê-lo durante a experiência migratória no Brasil, talvez em razão dela inclusive.

Maladi fetich é uma categoria bastante usada e com a qual me deparo com frequência nas conversas com os amigos haitianos, tanto no Haiti como na diáspora. Quando se referem a ela, apesar da razoável confiança que depositam na medicina científica hegemônica, estão apontando para a existência de certas doenças que só podem ser efetivamente curadas através de mecanismos "tradicionais" - ou aqueles que sejam capazes de interagir com as ações dos espíritos e do feitiço. Tais enfermidades, provocadas pela inveja de outras pessoas ou pela insatisfação dos espíritos poderiam ser, portanto, imunes aos medicamentos alopáticos. A ocorrência desses infortúnios pode resultar de múltiplos fatores que vão das próprias ações dos sujeitos às de terceiros. Podem derivar de omissões ou de atos que não sejam de responsabilidade direta do indivíduo, mas herdados de parentes já falecidos que não os podem mais remediar, por exemplo22.

A identificação dessa condição está ligada à percepção de uma ruptura na normalidade. Uma quebra com o estado de saúde natural da pessoa que supõe a manutenção da harmonia desta com os demais níveis da sua vida social, incluindo a relação com os mortos. Conhecer o porquê daquele sofrimento pessoal exige, portanto, um conhecimento aprofundado do sujeito, sua biografia, relações familiares, conflitos passados e da situação atual em que ele se encontra. O diagnóstico desse tipo de enfermidade pode compreender situações como: a insatisfação por parte de um certo antepassado, por ter sofrido uma má morte ou estar descontente diante da falta do cumprimento das obrigações pelos seus familiares vivos; feitiço lançado por familiares próximos ou pessoas distantes que se aproximaram em circunstâncias específicas (podendo ser o feitiço preparado pelos próprios malfektè yo, mal feitores), ou realizado através do serviço contratado de pessoas especializadas por jalouzi (inveja) incitada pelo bem estar econômico alheio; feitiço lançado pela mechanste (maldade) de terceiros que queiram se vingar diante da desconfiança de um mal causado pelo sujeito; castigo divino aplicado como correção diante dos mais diversos comportamentos que possam ser tidos enquanto impróprios; entre outras.

\footnotetext{
22 É bastante comum que as mazelas pessoais estejam associadas aos antepassados e a questões relacionadas a família de origem do afetado. Neste caso, elas são comumente adjetivas pelas palavras "rasyal" (racial) ou "rasin" (raiz), fazendo referência à ideia de raça no sentido de ancestralidade.
} 
É fato sabido entre os meus interlocutores que a condição migratória em si, pelo próprio fato do deslocamento para um outro país e das expectativas em torno de uma suposta prosperidade econômica alcançada pela diáspora, dá margem para muita inveja e desconfiança. Soma-se a isso as não raras dívidas contraídas quando não se consegue, na nova morada, cumprir com as obrigações frente aos familiares vivos e mortos. O desemprego e as graves dificuldades financeiras por que passam torna, muitas vezes, impossível a retribuição esperada pelos familiares que ficaram, e que participaram ativamente do planejamento da migração, contribuindo financeiramente para que ela ocorra, inclusive. Esses podem se sentir humilhados, rejeitados ou maltratados, desejando dar o troco àquele que os deixou. O desejo de destruição também pode vir dos espíritos (lwas) ressentidos, caso tenham sido esquecidos após serem acionados para garantir a proteção dos viajantes, por exemplo.

Há ainda a vulnerabilidade acrescida pela distância física entre o cotidiano imediato e os locais de referência onde se materializam tais relações com o universo de origem através de rituais, por exemplo. A dificuldade em voltar ou fazer visitas frequentes ao Haiti pode significar a impossibilidade de resolução de impasses que envolvem tais prestações. Ainda que o estatuto atribuído à maji (magia) e ao universo da mistik (místico) seja o de um saber partilhado sigiloso que, na maioria das vezes, todos fazem de conta não existir, e sobre o qual não se deve falar, a sua onipresença é inegável. A sua existência, apesar de invisível, é um fato da experiência, capaz de dirigir ações, pautar escolhas e afetar os corpos físicos, fluindo entre o que é imaterial e a própria matéria. Ela influi, assim, nos fluxos e contrafluxos, nas possibilidades de permanência e na necessidade de se mover.

Considerados força motriz dos processos de influência maligna associados ao temor de perseguição e ao desenvolvimento de uma maladi fetich, a inveja e a ambição desenfreadas - sempre relacionadas a situações de desigualdade e assimetria excessivas tendem a se manifestar enquanto elementos importantes da vivência migratória. Os imensos constrangimentos e violências que marcam o contexto em que se insere a recente aventura migratória dos haitianos no Brasil têm desencadeado situações que repõe desequilíbrios e desigualdades sociais profundas. Tal desordem também se reflete nas razões, sempre de ordem social, que afetam a saúde e o corpo físico da diáspora, para além das causalidades orgânicas que as doenças possam ter.

Assim como as guerras e outros eventos violentos como massacres e desastres irrompem na dinâmica social, afetando as relações entre os vivos e os mortos, a precariedade da condição dos imigrantes, ainda que em outra medida, também é capaz de causar um desequilíbrio espiritual que os deixa perigosamente expostos à animosidade da vingança e da perseguição. Ao refletir sobre as fragilidades específicas que encontrei em campo não pretendo de maneira nenhuma corroborar com a ideia de que o deslocamento seja, a priori, 
experiência propulsora de perturbações e distúrbios. Pelo contrário, ciente dos perigos de tal presunção, busco problematizar sobretudo as especificidades que incidem sobre a experiência daqueles que se movem através de condições claramente desfavoráveis. Quando o movimento é atravessado por diferentes ordens de violências, abusos e descriminações²3.

A doença, aqui, assim como a saúde, deve ser entendida de forma alargada. Ela não pode ser definida simplesmente como o oposto da ideia de saúde biomédica, ou seja, uma condição médica anormal, patológica, mas parece ser, ela mesma, uma espécie de sintoma, a manifestação de um problema de ordem também social que precisa ser superado. Caso contrário, a própria possibilidade de cura poderá estar impedida, independentemente dos critérios sensíveis da eficácia do tratamento biomédico. No caso de Joseph o tratamento farmacológico da enfermidade cardíaca identificada pelos médicos nunca havia ocupado a centralidade das preocupações da família, já que independentemente da sua eficácia, não resolver o problema que causara aquela condição impediria a sua cura integral, também do ponto de vista físico.

As conversas com os familiares de Joseph demonstram, por exemplo, a necessidade de refletirmos sobre a experiência em deslocamento através de uma perspectiva que busque superar a dicotomia entre o aqui e o lá (ou, se quiserem, entre o que é tomado como modernidade e aquilo que pertenceria ao domínio da tradição). A migração, em si, torna clara a complexidade dos arranjos culturais que vão compondo de forma contínua e interminável novos feixes de interpretação e possibilidades de ação frente aos infortúnios. Considerar os fenômenos da globalização não significa ignorar as continuidades existentes nas lógicas culturais e sociais que viajam junto com aqueles que se deslocam. Seja no Brasil ou no Haiti, há muito em comum entre as formas de explicar os mal-estares, individuais ou coletivos, experienciados diante das inúmeras inseguranças e ameaças vividas. Cabe a nós encontrar um caminho que nos permita reconhecer a historicidade das noções relativas às doenças de feitiço, sem que tenhamos que remetê-las a um universo tradicional culturalista e estático.

De forma bastante semelhante à clássica interpretação de Evans-Pritchard (1978[1937]) acerca da cosmologia "tradicional" e da bruxaria entre os Azande, no "sistema haitiano" (sistèm) ${ }^{24}$ nenhum infortúnio é fortuito. Acontecimentos indesejáveis como o adoecimento ou a morte são sempre algo que transcende o acidental, aleatório ou casual. Ainda que se considere as razões físicas e imediatas de um acontecimento, tais explicações sobre "como" as coisas aconteceram, não dão conta de explicar o "porquê" de terem

\footnotetext{
${ }^{23}$ Sobre a relação entre sofrimento e migração ver também Sayad (1999) e Bordomaro e Pussetti (2006).

${ }^{24}$ Expressão utilizada para se falar sobre um modo de agir próprio dos haitianos. Apesar de não ser sinônimo de vodu e nem substituir magia ou feitiçaria, é frequentemente empregada para se referir à identificação com o universo místico do Haiti (DALMASO, 2018, p. 98 e 114).
} 
ocorrido ou as suas circunstâncias específicas. A cosmologia haitiana exige e fornece uma resposta a essa pergunta. Tal resposta pode incluir a "vontade de Deus", já que a maioria dos haitianos professam a fé cristã, seja por influência do catolicismo (presente no país desde o período colonial) ou das igrejas protestantes e neopentecostais (em ascensão desde os anos da ocupação americana, entre 1915 e 1934). Independente dos arranjos mágico-religiosos que possam ser feitos, o importante é notar que no contexto em questão cada tormento provoca, inequivocamente, uma intensa reflexão sobre as relações sociais do sofredor no sentido de encontrar uma explicação possível para ele.

Em 2013, quando eu realizava pesquisa em Sassie, no Haiti, estive hospedada na casa do Tonton Dodo, um respeitado oungan, sacerdote vodu, que recebia diariamente em seu peristil (templo vodu) pessoas adoentadas em busca de cura. Elas vinham de várias regiões e podiam esperar por horas em grandes filas para serem atendidas. A sua atividade não se limitava a tratar a doença. Ele agia com o intuito de resolver, sobretudo, as razões - de ordem social - que diziam respeito aos infortúnios vividos e que teriam proporcionado o seu aparecimento. Ainda que o sujeito já tivesse ido ao hospital, na capital da província, ou consultado o agente de saúde da localidade, seguindo as orientações feitas, as investigações sobre as causas de uma doença envolviam sempre outras lógicas e relações de causalidade.

Tonton Dodo atuava todas as tardes como doktè fèy (doutor de folhas), o mesmo tipo de especialista procurado por Joseph ao retornar ao Haiti para se tratar. A sua prática envolvia a fabricação de medicamentos "tradicionais" preparados em garrafas para a utilização em banhos e chás terapêuticos. Detentor de invejáveis conhecimentos botânicos que acredito poderem ser reconhecidos inclusive à luz dos critérios farmacológicos da biomedicina, Tonton Dodo empreendia práticas diagnósticas e curativas - através da manipulação de fatores espirituais - que dificilmente seriam aceitas pela medicina oficial hegemônica. Vistos enquanto um conjunto de "superstições que atrelam o povo à ignorância", não é raro que se confunda a adoção de tais procedimentos com uma falsa aversão à medicina ocidental. No entanto, como podemos ver, mais do que uma relação de concorrência em que a maji se apresenta enquanto alternativa terapêutica, o que está em jogo aqui são diferentes concepções de saúde e doença que mobilizam, por sua vez, sistemas distintos, mas em constante relação.

As práticas "culturais" e os saberes "tradicionais" que fazem parte do repertório dos imigrantes com os quais convivi, em meio a um conjunto de crenças e comportamentos, em geral, bastante exotizados, são frequentemente situados em um polo oposto ao da racionalidade científica da biomedicina. Tidos enquanto discursos ilegítimos que colocam em risco as "boas práticas médicas", as narrativas dos próprios sujeitos sobre como eles pensam e vivem seus sofrimentos vão sendo reiteradamente desprezadas e negligenciadas. Imbuídos da ilusória tarefa de capturar e produzir a "verdade" sobre o corpo, as doenças ou a morte, 
postulando a primazia da dimensão biológica, os profissionais que atuam na área da saúde têm se habituado ao exercício de afastar os aspectos "culturais e religiosos" que, na melhor das hipóteses, podem ser considerados enquanto ficções discursivas, vazias de sentido real. Ao fazer isso, se afastam também da ideia de doença enquanto experiência (LANGDON, 2001), tão cara à antropologia.

Ao desenvolver uma reflexão antropologicamente sensível do "delicado" caso de Joseph, intencionei, ao longo destas páginas, percorrer a íntima relação estabelecida entre migração, saúde e religiosidade, a partir da manifestação da maladi fetich e do fenômeno mais amplo do "mal-estar" que emerge entre as redes que compõem o meu campo de pesquisa. Ao fazer isso, acredito contribuir para o desvendar de uma condição que escapa à grande parte da população não imigrante, aos médicos e profissionais da saúde e assistência, além dos pesquisadores mais especializados no tema migratório, que tendem a rejeitar tais narrativas ou situá-las enquanto barreiras culturais a serem vencidas. Encarar o tema do "malestar" e do sofrimento em deslocamento pressupõe uma articulação entre a antropologia da religião e a antropologia médica, entre os campos da saúde e da espiritualidade, que supere as polarizações entre magia, religião e ciência, de modo a não reduzir a complexidade dos fenômenos ao campo das representações simbólicas em oposição a uma "realidade" tomada enquanto objetiva.

Nesse sentido, escutar o que dizem aqueles de lá que vivem aqui significa não apenas retirar as suas narrativas da chave que as aprisiona ao primitivo, irracional e perigoso, situando-as na sua própria lógica de enunciação, mas considerá-las como aquilo que são para eles próprios, muito mais do que metáforas desimportantes. Esse exercício exige uma reflexão concomitante sobre as relações sociais mais invisíveis - sobretudo as relações desiguais e de exploração - que se articulam com as afirmações, por vezes aparentemente contraditórias, sobre a dimensão mística e afetiva do conhecimento. Ao acionar a semântica da magia, assim como fazem meus interlocutores, quero apontar também para o plano da ação, da prática, do fazer, daquilo que se produz ao longo da experiência migratória e não apenas à forma de se pensar sobre ela. Pensar e viver configuram a experiência e não podem ser separados. Se quisermos, portanto, nos aproximar da vivência desses sujeitos precisamos, antes de mais nada, levar a sério as suas narrativas com a mesma seriedade e convicção com a qual eles nos falam sobre elas.

Voltando à pergunta que me foi feita por Sylvie sobre o que teria realmente causado a morte de Joseph, pergunta que abre a primeira sessão desse texto, não creio que o esperado de mim fosse precisamente julgar serem falsas ou reais as suas suspeitas. Não estaria eu em posição de opinar assertivamente, tendo o conhecido tão brevemente. Ela questionava sobre o fato mais imediato - cirurgia no coração, atropelamento, agressão? -, mas não tinha dúvidas acerca da perseguição enfrentada por ele, maladi fetich, causa 
subjacente ao que teria provocado a sua morte num nível mais aparente. Os perigos são muitos e têm lógicas materiais próprias, mas só atingem os seres humanos devido a razões sociais mais profundas com as quais devemos nos preocupar com seriedade, sejam elas a conflituosidade dos vivos ou a falta de harmonia com os mortos - que são concebidos enquanto uma parte integrante da sociedade e das relações que nela se estabelecem. Essa perspectiva me parece mobilizar dinâmicas estruturais perversas que não estão separadas do plano mais concreto das violações sofridas por ele em solo brasileiro, aquelas que, sim, pude testemunhar concretamente, ao menos em parte.

Ao me debruçar sobre essas narrativas me interesso, sobretudo, pelas respostas produzidas no espaço migratório para os percalços nele enfrentados. Nesse sentido, medos e temores associados à exclusão e à despossessão, já bem conhecidos em um nível local, vão sendo recolocados por esses sujeitos em diáspora. As explicações e possíveis reações vão sendo forjadas a partir da própria historicidade haitiana e da experiência no novo contexto, movimento que supõe tanto rupturas e transformações quanto continuidades com aquele universo. Assim, aspectos do universo mágico-religioso presentes na subjetividade dos imigrantes não são apenas um dispositivo discursivo alternativo ao oficial no processo de interpretação e significação da experiência do "mal-estar" e do adoecimento, mas apontam para o fundamento social daquilo que muitas vezes ao adentrar o campo da saúde é tomado unicamente na sua dimensão natural ${ }^{25}$.

A maladi fetich manifesta na trajetória de Joseph endereça um sofrimento que é a um só tempo individual, social e político. Nesse sentido, ela não é necessariamente uma doença, em termos orgânicos. É, antes, algo que indica uma desordem no campo espiritual e social, que coloca o corpo em relação com o mundo social. Ela capta, através de um idioma condizente com a experiência cultural dos imigrantes, os seus anseios e medos diante das incertezas de adentrar a dinâmica de ameaças reais de tal contexto inegavelmente adverso. Ao levá-la a sério, não apenas como metáfora do que experienciam, podemos compreender a vivência cotidiana do sofrimento em deslocamento (expressa de forma generalizada pela expressão pase mizè) em relação a toda uma história mais ampla de insultos, vexações e desigualdades.

\section{REFERÊNCIAS}

\section{AZEVEDO, Celia Maria Marinho de. Onda negra, medo branco: 0 negro no imaginário das elites - século XIX. Rio de Janeiro: Paz e Terra, 1987.}

${ }^{25}$ Sobre a produção social dos corpos enquanto objeto de invenção de saberes e lugar de manifestação do poder, ver Fassin e Memmi (2004). 
BAENINGER, R.; PERES, R.; FERNANDES, D.; SILVA, S. et al. (Orgs.). Imigração haitiana no Brasil. Jundiaí (SP): Paco Editorial, 2016.

BERSANI, Ana Elisa. 0 (extra)ordinário da ajuda: histórias não contadas sobre desastre e generosidade na Grand'Anse, Haiti. Dissertação (Mestrado) - Programa de Pós-Graduação em Antropologia Social, Universidade Estadual de Campinas (Unicamp), 2015.

BERSANI, Ana Elisa. "Chache lavi Deyò: uma reflexão sobre a categoria refúgio a partir da diaspora haitiana no Brasil". Cadernos de Campo, São Paulo, n. 25, p. 383-399, 2016.

BERSANI, Ana Elisa; HANDERSON, Joseph. Apresentação: 0 Brasil e a diáspora haitiana. Temáticas, Campinas, v. 25, n. 49/50, p. 9-16, 2017.

BORDOMARO, Lorenzo; PUSSETTI, Chiara. "Da utopia da migração à nostalgia dos imigrantes: percursos migratórios entre Bubaque (Guinea Bissau) e Lisboa". In: Antónia Pedroso de Lima e Ramon Sarró (eds.), Terrenos metropolitanos: ensaios sobre produção etnográfica. Lisboa: Imprensa de Ciências Sociais, 2006. p. 125-153.

CAVALCANTI, L. "Novos fluxos migratórios: haitianos, senegaleses e ganenses no mercado de trabalho brasileiro". In: GEDIEL, José Antônio Peres; GODOY, Gabriel Gualanao de (Org.). Refúgio e hospitalidade. Curitiba: Kairós, 2016. p. 231-247.

DALMASO, Flávia. Heranças de família: terras, pessoas e espíritos no sul do Haiti. Mana, v. 24, n. 3, p. 96-123, 2018.

DUARTE, Luiz Fernando Dias. Da vida nervosa nas classes trabalhadoras urbanas. Zahar, 1988.

DUARTE, Luiz Fernando Dias. "A outra saúde: mental, psicossocial, físico-moral”. In: DUARTE, Luiz Fernando Dias. Saúde e doença: um olhar antropológico. Rio de Janeiro, Fiocruz, 1994. p. 83-90.

EVANS-PRITCHARD, E. E. Bruxaria, Oráculos e Magia entre os Azande. Rio de Janeiro: Zahar, 1978 [1937].

FASSIN, Didier. Humanitarian Reason: a moral history of the present. University of California Press, 2012.

FASSIN, Didier; MEMMI, D. Le gouvernement des corps. Éditions de l'École des hautes études en sciences sociales, Paris, 2004.

FELDMAN-BIANCO, Bela. 0 Brasil frente ao regime global de controle das migrações: Direitos humanos, securitização e violências. Travessia - Revista do Migrante, v. 31, n. 83, p. 11-36, 2018.

FERNANDES, D; MILESI, R; FARIAS, A. Do Haiti para o Brasil: o novo fluxo migratório. Cadernos de Debates, n. 6, p. 73-97, 2012.

FOUCAULT, Michel. Em defesa da sociedade: curso no Collège de France. Tradução de Maria Ermantina Galvão. São Paulo: Martins Fontes, 1999.

FOUCAULT, Michel. Segurança, Território, População: curso no Collège de France (1977-1978). Tradução de Claudia Berliner. São Paulo: Martins Fontes, 2008. 
FREUD, S. 0 mal-Estar na civilização. Edição Standard Brasileira das Obras Psicológicas Completas de Sigmund Freud, Vol. 21. Rio de Janeiro: Imago, 1996 [1929].

HANDERSON, J. Diaspora, as dinâmicas da mobilidade haitiana no Brasil, no Suriname e na Guiana Francesa. Tese (Doutorado) - Programa de Pós-Graduação em Antropologia Social, Universidade Federal do Rio de Janeiro (UFRJ), 2015a.

HANDERSON, J. Diaspora. Sentidos sociais e mobilidades haitianas. Horizontes Antropológicos, v. 21, n. 43, p. 51-78, 2015b. Disponível em: http://dx.doi.0rg/10.1590/S0104-71832015000100003

HANDERSON, J. "Diaspora, circulation et mobilité: les jeunes Haïtiens au Brésil". In: Louis Herns Marcelin; Toni Cela; Dorvil Henri (orgs.), Les jeunes Haïtiens dans les Amériques // Haitian youth in the Americas. Collection Problèmes sociaux et interventions sociales. Montréal: Presses de l'Université du Québec (PUQ), 2017.

HURBON, L. "Le statut du vodou et l'histoire de l'anthropologie". Gradhiva, 1:153 -163, 2005.

LANGDON, Jean. A doença como experiência: 0 papel da narrativa na construção sociocultural da doença. Etnográfica, v. 5, n.2, p. 241-260, 2001.

MORO, Marie Rose. Psicoterapia transcultural da migração. Psicologia USP, v. 26, v. 2, p. 186-192, 2015.

NATHAN, T. La folie des autres. Traité d' ethnopsychiatrie Clinique, Paris: Ed. Dunod, 1986.

NEIBURG, Federico (Org). Conversas etnográficas haitianas. Rio de Janeiro: Papéis Selvagens Edições, 2017.

PATARRA, Neide L. 0 Brasil: país de imigração? Revista eletrônica e-metropolis, v. 3, n. 9, p. 65-96, 2012.

RAMSEY, Kate. Prohibition, persecution and performance: anthropology and the penalization of vodou in the mid-twentieth century. Gradhiva, n. 1, p. 165-179, 2005.

RICHMAN, K. Migration and Vodou. Gainesville (EUA): University Press of Florida, 2005.

SARRÓ, Ramon. Órganos vitales y metáforas mortales: Un relato sobre hospitaçes portugueses y diáspora africana. Revista de Antropología Social, n. 16, p. 325-348, 2007.

SARTI, Cynthia. Corpo e doença no trânsito de saberes. Revista Brasileira de Ciências Sociais, v. 25, n. 74, p. 77-90, 2010.

SAYAD, A. La double absence: des illusions de l'émigré aux souffrances de l'immigré. Paris: Ed. Seuil, 1999.

SEYFERTH, Giralda. Colonização, imigração e a questão racial no Brasil. Revista USP, São Paulo, n. 53, p. 117-149, 2002. 